\title{
IMPACTOS DAS EMENDAS CONSTITUCIONAIS NOS PROCESSOS DE APOSENTADORIA VOLUNTÁRIA DOS PROFESSORES DAS UNIVERSIDADES FEDERAIS: GESTÃO DA INFORMAÇÃO
}

\author{
IMPACTS OF THE CONSTITUTIONAL AMENDMENTS \\ ON THE PROCESSES OF THE VOLUNTARY \\ RETIREMENT FROM THE PROFESSORS AT THE \\ FEDERAL UNIVERSITIES: INFORMATION \\ MANAGEMENT.
}

Rosaura Maria Barbosa Mesquita Neivaa Nadi Helena Presser ${ }^{b}$ Raimundo Nonato Macedo dos Santosc Francisco Jatobá Andraded

\begin{abstract}
RESUMO
Introdução: Aposentadoria voluntária é um tipo de aposentadoria concedida aos servidores que completaram os requisitos mínimos estabelecidos na Constituição Federal. Objetivo: Analisa as relações entre as aposentadorias voluntárias concedidas na universidade e as mudanças estabelecidas nas Emendas Constitucionais à Constituição Federal de 1988, desde sua apresentação ao Congresso Nacional até a sua promulgação. Metodologia: Pesquisa descritiva e explicativa, buscou uma relação entre dois fenômenos: aposentadoria dos professores e Emendas à Constituição de 1988 que tratam do assunto. A coleta de dados foi realizada por meio de pesquisa documental e na base de dados do Sistema Integrado de Administração de Pessoal (SIAPE). Resultados: A pesquisa aponta que existe uma relação direta entre os pedidos de aposentadoria voluntária e as mudanças nas regras de aposentadoria, já no
\end{abstract}

a Graduada em Comunicação Visual pela Universidade Federal de Pernambuco (UFPE). E-mail: zaumesquita@gmail.com.

b Doutora em Engenharia de Produção pela Universidade Federal de Santa Catarina (UFSC). Docente no Programa de Pós-Graduação em Ciência da Informação e no Mestrado Profissional em Desenvolvimento e Gestão Pública da Universidade Federal de Pernambuco (UFPE). Email: nadiheleana@uol.com.br.

c Doutor em Information Stratégique Et Critique Veille Technol - Université Paul Cézanne Aix Marseille III. Docente da Universidade Federal de Pernambuco (UFPE). E-mail: rnmacedo@uol.com.br.

d Doutor em Sociologia pela Universidade de São Paulo (USP). Docente do Departamento de Sociologia da Universidade Federal de Pernambuco (UFPE). E-mail: franciscojatoba@gmail.com. 
início da tramitação das Emendas. Conclusões: Houve um impacto nas solicitações de aposentadorias voluntárias, da ordem de $223 \%$ a mais de pedidos em relação às demandas que ocorriam em anos anteriores ao início das mudanças introduzidas por meio de Emendas à Constituição Federal de 1988.

Descritores: Aposentadoria voluntária de professores. Universidade Pública Federal. Emendas à Constituição de 1988. Gestão da Informação.

\section{INTRODUÇÃO}

A aposentadoria é um benefício assegurado ao servidor público que completar os requisitos estabelecidos em lei. É, inclusive, uma das formas de vacância do cargo efetivo do servidor público, para a pessoa legalmente investida em cargo público criado por lei, de provimento efetivo (BRASIL, 2017).

A aposentadoria de um trabalhador, seja ele da iniciativa privada ou da esfera pública, é um fenômeno que impacta em diversas áreas, como a vida pessoal e familiar, uma vez que poderá trazer consequências financeiras e emocionais, na sociedade como um todo, em virtude da relação direta com o mercado de trabalho, bem como nas próprias organizações, quando afeta 0 prosseguimento do trabalho.

Atualmente, no contexto do Brasil (2017), são três os tipos de aposentadoria vigentes:

a. Aposentadoria Compulsória: devida ao servidor, ao ter completado determinada idade, independente de sexo. Ou seja, o servidor será aposentado, obrigatoriamente, com proventos proporcionais ao tempo de contribuição, a partir do dia posterior ao de ter completado a idade limite para permanência no serviço público, atualmente, 75 anos de idade. A Lei Complementar n 152, de 3 de dezembro de 2015 (BRASIL, 2015b), alterou o limite de permanência no serviço público determinado no inciso II do $\S 1 \cong$ do art. 40 da Constituição Federal (BRASIL, 1988), de 70 para 75 anos.

b. Aposentadoria por Incapacidade Permanente: devida ao servidor que se encontra permanentemente incapacitado de exercer atividade laboral e 
que também não possa ser readaptado em outro cargo, de acordo com a avaliação da perícia oficial. O benefício é pago enquanto persistir a incapacidade, sendo obrigatória a realização de avaliações periódicas da condição da incapacidade. Os proventos serão proporcionais ao tempo de contribuição, exceto se decorrente de acidente em serviço, moléstia profissional ou doença grave, contagiosa ou incurável, na forma da lei.

c. Aposentadoria Voluntária: concedida ao servidor, a seu pedido, após cumprir os requisitos estabelecidos na Constituição Federal e em lei.

Esta pesquisa teve como foco de observação e análise uma universidade pública federal. $O$ objeto de análise foram as informações registradas e disponibilizadas pelo Sistema Integrado de Administração de Pessoal (SIAPE), relativas aos processos de aposentadoria voluntária dos professores de Magistério Superior, no período compreendido entre 1989 até 2019. A aposentadoria voluntária é o único tipo que ocorre por vontade e decisão do servidor, mesmo que seja uma decisão tomada tempestivamente pela incerteza do futuro ou, mesmo, pela certeza de que seus direitos seriam suprimidos ou reduzidos.

O SIAPE foi instituído por meio do Decreto n 99.328 , de 19 de junho de 1990 (BRASIL, 1990), e operam, nesse sistema de informação, outros órgãos federais, além das universidades. Dentre outras finalidades do SIAPE, a principal é integrar e uniformizar procedimentos de cadastro e pagamento das ações relativas aos servidores ativos, aposentados, beneficiários de pensão civil, pensão alimentícia, os contratados regidos pela Lei n 8.745 , de 9 de dezembro de 1993 (BRASIL, 1993b), e atualmente os estagiários e os residentes, além de dar suporte às atividades de gestão de recursos humanos. Até então, cada órgão realizava a gestão de orçamento e recursos humanos de forma isolada.

A Instrução Normativa n 04/2006 (BRASIL, 2006) elencou como um dos objetivos do SIAPE, a construção de uma base de dados para a geração e emissão da folha de pagamento unificada e do histórico funcional e financeiro dos servidores. Além das finalidades normativas do SIAPE, as informações nele 
produzidas podem servir a outros fins gerenciais, como a que se propõe este estudo no contexto da Gestão da Informação.

O SIAPE está organizado em módulos, dentre eles, o módulo de aposentadoria, em que são cadastradas todas as informações necessárias para a concessão da aposentadoria. Desde o ingresso do servidor no órgão, informações pessoais e funcionais são armazenadas no sistema, bem como todas aquelas produzidas ao longo da sua vida funcional - promoções, progressões, ausências, afastamentos, licenças, férias, designação de função , gerando o banco de informações de cada servidor e que será base para a concessão de sua futura aposentadoria (BRASIL, 2017). Com apoio nessas informações, bem como aquelas referentes ao tempo de serviços em outras organizações que cada servidor poderá averbar em sua pasta funcional, o sistema automaticamente realiza a alteração da situação funcional do servidor de "ativo", até sua situação de "aposentado".

Com a aposentadoria efetivada, a vaga do servidor pode, a critério da administração, do limite autorizado para o quadro de docente do órgão e da informação prévia ao órgão central do Sistema de Pessoal Civil da Administração Federal (SIPEC), ser utilizada para novo provimento (BRASIL, 2017). Por essa razão, nas universidades públicas federais, a aposentadoria não é só um direito do servidor público, também se transforma em uma medida de gerenciamento dos provimentos das vagas dos cargos dos aposentados, dos concursos públicos para o processo seletivo e das nomeações dos cargos. Todavia, a abertura de concursos públicos e a reposição de vagas dos professores de Magistério Superior vêm, ao longo dos anos, se tornando cada vez mais restritivas e impositivas por parte dos órgãos superiores do SIPEC. Por outro lado, a saída antecipada de professores traz uma perda do capital intelectual e estrutural de uma universidade. Ademais, para estruturar e gerir organizações como as universidades e atender às especificidades de aposentadoria do seu quadro de professores, se faz necessário assegurar que as novas vagas sejam ocupadas em tempo hábil por profissionais qualificados.

Por isso, o problema desta pesquisa envolveu um tema bastante atual e 
polêmico, e também uma questão prática, para a qual se identificaram as informações geradas pelos processos de aposentadoria da universidade, relacionando-as com as alterações na legislação previdenciária, questão essa da seguinte ordem: Qual o impacto das mudanças trazidas pelas emendas à Constituição de 1988, na legislação previdenciária e nas regras de aposentadoria, nos pedidos de aposentadoria voluntária, tomando para análise o período de 1993 a 2019?

Logo, o objetivo geral desta pesquisa foi analisar as relações entre as aposentadorias voluntárias concedidas na universidade e as mudanças estabelecidas nas Emendas Constitucionais à Constituição Federal de 1988, desde sua apresentação ao Congresso Nacional até a sua promulgação.

No campo da Ciência da Informação, este estudo mostrou a potencialidade da gestão das informações registradas nos processos de aposentadoria solicitados ao longo de um período e armazenadas nos sistemas de informações da universidade. Como defende Johnson (2009), os gestores organizacionais, e aqui estende-se às universidades, não deveriam ignorar as informações existentes em seus bancos de dados e, ainda mais, poderiam utilizá-las para a busca de melhorias em cada área específica.

No contexto das universidades públicas federais, as informações produzidas são registradas nos documentos gerados por cada órgão, na forma de ofícios, memorandos, laudos, pareceres, sistemas informatizados e tantos outros, que posteriormente irão compor os processos administrativos. Tais documentos implicam, portanto, na formalização dos processos. Os processos de aposentadoria funcionam mediante registro, disseminação e uso de uma quantidade significativa de informações. Cada processo (de aposentadoria compulsória, voluntária ou por incapacidade permanente) tem suas etapas de atividades, as quais funcionam mediante um fluxo de informação que the é peculiar. São as informações registradas em cada etapa do processo e o seu fluxo, que são objeto de gestão da informação.

Infelizmente, a gestão da informação ainda é um recurso inacessível para muitas organizações que não desenvolveram habilidades para capitalizar e usar 
as informações que produzem ou a que têm acesso. Os autores que apresentam modelos de gestão de informação (LE COADIC, 2004; BEAL, 2004; DAVENPORT; PRUSAK, 1998; CHOO, 1998; MCGEE; PRUSAK, 1994) colocam ênfase no uso da informação. Mas foi Fleming-May (2008) quem identificou a ampla gama de significados e a pouca clareza do conceito de uso da informação. A autora traçou dimensões e atributos do conceito para prover um quadro teórico para auxiliar no entendimento do uso da informação no âmbito das bibliotecas, e que se aplica em qualquer ambiente, como neste estudo, delimitado à universidade pública federal.

A noção, a priori, da multidimensionalidade do conceito de uso se constitui como o pano de fundo para discorrer sobre três categorias de estudo identificadas na literatura por Fleming-May (2008):

a. o que é uso, dimensão teórica;

b. o quanto se usa, dimensão avaliativa;

c. quem usa, dimensão centrada no usuário, que considera o impacto do uso no cotidiano do usuário na organização onde atua.

Nas conclusões de Fleming-May (2008), o estudo teórico prioriza aspectos gerais, filosóficos e discussões teóricas sobre o uso; o estudo avaliativo está voltado à mensuração da ação de uso associado com um tipo particular de fonte (p. ex. sistema SIAPE e legislações), ou serviços (p. ex., relatório do SIAPE) para fins de avaliação; já o estudo centrado no usuário leva em consideração o impacto do uso, por exemplo, na gestão das vagas de provimento de servidores na universidade.

\section{PREVIDÊNCIA SOCIAL E APOSENTADORIA DOS SERVIDORES PÚBLICOS NO BRASIL}

No Brasil, o conjunto de políticas de Saúde, Previdência e Assistência Social é denominado de Seguridade Social, conforme o art. 194 da Constituição Federal brasileira. A Constituição Federal de 1988 prevê e a Lei nº. 8.212, de 24 de julho de 1991 (BRASIL, 1991), regulamenta e conceitua a Seguridade Social como um conjunto integrado de três elementos compostos de: previdência social, 
assistência social e assistência à saúde.

Atualmente no Brasil a Previdência Social é composta de três regimes, como mostra o Quadro 1.

Quadro 1 - Regimes da Previdência Social no Brasil

\begin{tabular}{|l|l|}
\hline \multicolumn{1}{|c|}{ Regimes } & \multicolumn{1}{|c|}{ Definição } \\
\hline $\begin{array}{l}\text { Regime Geral de } \\
\text { Previdência Social } \\
\text { (RGPS) }\end{array}$ & $\begin{array}{l}\text { Entidade pública e de filiação obrigatória para os } \\
\text { trabalhadores regidos pela CLT }\end{array}$ \\
\hline $\begin{array}{l}\text { Regime Próprio de } \\
\text { Previdência Social } \\
\text { (RPPS) }\end{array}$ & $\begin{array}{l}\text { Institutos de Previdência ou Fundos Previdenciários e de } \\
\text { filiação obrigatória para os servidores públicos titular de } \\
\text { cargos efetivos da União, dos Estados, do Distrito Federal e } \\
\text { dos Municípios }\end{array}$ \\
\hline $\begin{array}{l}\text { Regime de Previdência } \\
\text { Complementar (RPC) }\end{array}$ & $\begin{array}{l}\text { Operado por Entidades Abertas e Fechadas de Previdência } \\
\text { Complementar, regime privado, com filiação facultativa, } \\
\text { criado com a finalidade de proporcionar uma renda adicional } \\
\text { ao trabalhador, que complemente a sua previdência oficial. }\end{array}$ \\
\hline
\end{tabular}

Fonte: Funpresp-Exe (2019).

Como se vê, os servidores públicos titulares de cargos efetivos, como os professores das universidades, estão assegurados pelo Regime Próprio de Previdência Social (RPPS), cuja filiação é obrigatória a partir do ato de sua nomeação, posse e exercício, e, em vista disso, esta seção se restringirá aos marcos de alteração legal referente apenas ao RPPS.

A primeira previsão legal para concessão de aposentadoria para servidores públicos ocorreu na Constituição da República de 1891, apenas em casos de invalidez por acidente em serviço. Posteriormente, a Constituição de 1934, a Constituição de 1946, a Constituição de 1967 e a última Constituição Federal de 1988, vigente atualmente, todas trouxeram contribuições ao sistema previdenciário. Até a promulgação da Constituição de 1988, a proteção social dos servidores públicos era tratada como uma extensão da política de pessoal do Estado. Isto é, tratava-se de um prêmio a ser outorgado aos servidores, em retribuição às várias décadas de serviços prestados ao Estado (PORTO; CAETANO, 2015).

Porém, a legislação previdenciária foi sendo sistematicamente alterada desde a promulgação da Constituição Federal de 1988. E, as alterações fixaram 
critérios mais rígidos para a concessão de benefícios tanto pelos regimes próprios de previdência social, bem como pelo RGPS, tutelado pelo Instituto Nacional do Seguro Social (INSS). As alterações à Constituição de 1988 foram estabelecidas por meio de várias Emendas Constitucionais, tendo sido alvo as alterações no seu artigo 40, que trata das regras de aposentadoria.

De acordo com Lourenço, Lacaz e Goulart (2017), além das contrarreformas da Previdência Social nos governos do Presidente Fernando Henrique Cardoso, Lula e Dilma, é no governo Temer que se constrói a crise fiscal do Estado e ocorre uma forte ofensiva do capital financeiro para destruir os direitos sociais tanto trabalhistas como previdenciários. Munido do principal argumento de que o sistema previdenciário é deficitário (FAGNANI, 2016), o Executivo Federal, em 2016, por meio da Proposta de Emenda Constitucional PEC n 287/2016 (BRASIL, 2016), tentou, mas não conseguiu, implementar a reforma na Previdência Social.

Todavia, no governo Bolsonaro, a Emenda Constitucional n¹03/2019 (BRASIL, 2019b), a mais profunda reforma da Previdência Social feita no país desde a Constituição Federal de 1988, alterou o sistema previdenciário e impôs regras de transição. Entre outros pontos, a reforma adotou uma idade mínima de aposentadoria tanto para quem trabalha na iniciativa privada, como para servidores públicos. Além disso, mudou regras de cálculo para o valor do benefício, instituiu normas de transição para os trabalhadores da ativa e alterou o sistema de pensões.

As Emendas Constitucionais têm alterado as regras de aposentadorias no sentido de impor mais exigências ao servidor e aumentar os períodos de contribuição. Em geral, as respostas dos governos têm uma dimensão técnica, mas dependem também da visão ideológica e de interesses de quem as formula. No Brasil atual, é forte a influência dos defensores de um Estado mínimo, com menos proteção aos cidadãos, com o argumento de que isso resultaria em diminuição da carga tributária.

Fazio (2019) é um analista que entende que o cerne do debate não é apenas técnico, mas diz respeito à revisão do 'pacto social' selado na 
Constituição Federal de 1988 e do reconhecimento dos chamados 'direitos sociais', que são os direitos que visam garantir a cada membro da sociedade condições mínimas de vida digna por meio de políticas públicas, que limitam a desigualdade socioeconômica. A Constituição de 1988 estabelece no art. 6ำ que são direitos sociais, entre outros, a educação, a saúde, a alimentação, o trabalho e a previdência social.

Portanto, a rigor, o RGPS é instrumento de políticas distributivas, conforme disposto na Constituição Federal, que define a Previdência Social como 'direito social. Por isso, na avaliação de Fazio (2019), fazem sentido os subsídios previdenciários concedidos a alguns segmentos de segurados, com destaque para os trabalhadores rurais em regime de agricultura familiar, as mulheres, os professores, as donas de casa sem remuneração, os microempresários individuais, dentre outros.

Tecnicamente, tais subsídios são financiados pelas receitas adicionais do Estado previstas no art. 195 da Constituição Federal, entre eles, recursos orçamentários, Programa de Integração Social (PIS), Programa de Formação do Patrimônio do Servidor Público (PASEP), Contribuição Social sobre o Lucro Líquido (CSLL), Contribuição para o Financiamento da Seguridade Social (COFINS), Loteria Federal, entre outros (FAZIO, 2019, p. 5, nota de rodapé).

Porém, há de se considerar que o conjunto de mudanças na previdência, por força das emendas constitucionais aplicadas, tem sido fator determinante para o aumento expressivo de solicitações de aposentadoria dos professores do magistério superior, cujos reflexos na avaliação do resultado do processo de reposição das vagas não têm sido objeto análise das consequências do ponto de vista de perdas e danos, relativas aos bens intangíveis, partes inerentes do processo.

Assim, faz-se necessário considerar que, na reposição de um professor universitário que se aposenta, particularmente nos casos das aposentadorias voluntárias, o impacto não está limitado somente ao seu setor de lotação ou à sala de aula, mas atinge a universidade como um todo, compreendendo, além das atividades de ensino, também de pesquisa e extensão, ao mesmo tempo em 
que o saber acumulado pelo professor em tantos anos de profissão é subtraído do conjunto de saberes da universidade. Fala-se, neste caso, da subtração dos saberes dos docentes nos cursos de graduação que têm seu corpo docente formado exclusivamente por servidores efetivos.

Soma-se a questões dessa ordem o próprio processo de seleção e contratação de novos docentes. Atualmente, a nomeação de um professor depende do atendimento das determinações do Decreto 9.739 de 2019 (BRASIL, 2019a) para a realização de concursos públicos e do Decreto $n^{\circ} 7.485$ de 18/05/2011 (BRASIL, 2011), que criou o Banco de Professor Equivalente.

O Banco de Professor Equivalente é constituído pela soma dos professores do magistério superior e dos titulares livres do magistério superior, efetivos, substitutos e visitantes, atribuindo a cada tipo e de acordo com sua jornada de trabalho um valor de referência que, após a operação total, determinará o valor máximo que poderá ser usado para nomeações de professores, desde que haja código de vaga livre e que seja comunicado com antecedência ao Ministério da Economia. O banco pode sofrer alteração tanto dos fatores de referência, como do quantitativo de vagas.

O artigo $4^{\circ}$ do Decreto 9.739 de 2019 (BRASIL, 2019a) inclui o item III do $\S 2$ - realização de concursos públicos e de provimento de cargos públicos - no rol de matérias que precisam ser apresentadas pelo órgão ao Ministério da Economia, até 31 de maio de cada ano, para inclusão no projeto de lei orçamentária para o ano seguinte. As propostas de autorização para realização de concurso público devem atender a quatorze itens de informações presentes no art. $6^{\circ}$ do referido Decreto. $O$ provimento de cargo de professor em instituições federais de ensino superior deve observar o limite do Banco de Equivalência, o quantitativo de cargos vagos no órgão para o quadro de docente e a informação prévia ao órgão central do SIPEC. Ainda assim, a reposição da vaga de um professor que se aposenta não necessariamente ocorrerá para 0 mesmo departamento. Considerando que os códigos de vagas passaram a compor o Banco de Equivalência de cada universidade, as vagas passam a pertencer à Universidade e não ao departamento, podendo a Reitoria decidir, 
segundo critérios, onde alocar a vaga.

Como já afirmou Choo (1998), nas organizações, ações e decisões não são o resultado simples de uma atividade única e ordenada, elas emergem de uma ecologia de processos de informação. Corroborando com o autor, é só observar a sequência de eventos que se sucedem dentro das universidades após uma aposentadoria, para se ter uma ideia da diversidade de participantes e de pontos de vista que necessitam negociar juntos, mas que também desafiam uns aos outros.

\section{PROCEDIMENTOS METODOLÓGICOS}

Quanto aos objetivos fixados, esta é uma pesquisa descritiva e explicativa (VERGARA, 2016). Descritiva porque identificou os períodos de maiores concessões de aposentadorias, correlacionando-as com os períodos de mudanças de legislação previdenciária e alteração das regras de aposentadoria. É explicativa, uma vez que buscou uma relação de causa e efeito sobre dois fenômenos: as aposentadorias e as mudanças das legislações sobre o assunto. A pesquisa explicativa tem como objetivo básico a identificação dos fatores que determinam ou que contribuem para a ocorrência de um fenômeno (GIL, 2008).

Inicialmente, a coleta dos dados foi viabilizada por intermédio de fontes documentais. Nesse caso, adotou-se como referência as publicações da legislação previdenciária e das regras de aposentadoria a partir da Constituição Federal de 1988, considerando como foco de análise as Emendas à Constituição de 1988 que trouxeram alterações nas regras de aposentadorias, conforme se apresentam a seguir:

I. EC 03/1993 (BRASIL, 1993a).

II. EC 20/1998 (BRASIL, 1998).

III. EC 41/2003 (BRASIL, 2003).

IV. EC 47/2005 (BRASIL, 2005).

V. EC 103/2019 (BRASIL, 2019b).

A EC 88/2015 (BRASIL, 2015a) foi desconsiderada de toda a análise, uma vez que só trata do tipo de aposentadoria compulsória. A partir do estudo das 
Emendas Constitucionais, foram formadas duas categorias como chaves analíticas dos dados extraídos da base de dados da universidade objeto deste estudo (Quadro 2).

A primeira categoria, denominada de "Tramitação", se refere ao tempo que cada Proposta de Emenda Constitucional (PEC) passou tramitando desde a sua apresentação ao Congresso Nacional até a sua promulgação. Essa categoria é essencial, pois, uma vez que a notícia de uma nova PEC se torna pública, surgem as incertezas e dúvidas sobre o impacto que trará para os envolvidos. A outra categoria, "Impacto das Mudanças", analisa o impacto das alterações propostas pelas Emendas Constitucionais relativas às aposentadorias dos servidores públicos.

Quadro 2 - Categorias de análise

\begin{tabular}{|c|c|c|c|}
\hline $\begin{array}{l}\text { Categorias } \\
\text { de Análise }\end{array}$ & Definição & Tipos & Definição \\
\hline \multirow{2}{*}{$\begin{array}{l}\text { Tempo de } \\
\text { Tramitação }\end{array}$} & \multirow{2}{*}{$\begin{array}{l}\text { Tempo que cada PEC } \\
\text { passou tramitando desde } \\
\text { a entrega do projeto ao } \\
\text { Congresso até a sua } \\
\text { promulgação }\end{array}$} & Longo & \multirow{2}{*}{$\begin{array}{l}\text { Em ambos os tipos, } \\
\text { considera-se o tempo de } \\
\text { tramitação desde a } \\
\text { apresentação da PEC ao } \\
\text { Congresso Nacional até } \\
\text { a sua promulgação. }\end{array}$} \\
\hline & & Curto & \\
\hline \multirow{2}{*}{$\begin{array}{l}\text { Impacto das } \\
\text { Mudanças }\end{array}$} & \multirow{2}{*}{$\begin{array}{l}\text { Analisa o impacto das } \\
\text { alterações propostas } \\
\text { pelas Emendas } \\
\text { Constitucionais relativas } \\
\text { às aposentadorias dos } \\
\text { servidores públicos. }\end{array}$} & Estrutural & $\begin{array}{l}\text { Quando a Emenda } \\
\text { Constitucional impacta } \\
\text { em três ou mais } \\
\text { variáveis. }\end{array}$ \\
\hline & & Incremental & $\begin{array}{l}\text { Quando a Emenda } \\
\text { Constitucional impacta } \\
\text { em, no máximo, duas } \\
\text { variáveis. }\end{array}$ \\
\hline
\end{tabular}

Fonte: Neiva (2020).

A partir dos estudos sobre as Emendas Constitucionais, inicialmente foram identificados os pontos-chave das alterações propostas que causaram os maiores impactos nas aposentadorias. Assim, em relação aos tipos de mudança (se Estrutural ou Incremental), as principais variáveis consideradas são as que se seguem e que passaram a compor a chave de análise da categoria Impacto nas Mudanças:

a. Alteração da idade para a aposentadoria; 
b. Alteração do tempo para a aposentadoria;

c. Alteração da contribuição previdenciária;

d. Alteração da fórmula de cálculo dos proventos;

e. Exclusão de direitos concedidos.

Outra fonte de coleta de dados foi o sistema de informações SIAPE, utilizado pela UFRPE como base de armazenamento de dados dos processos de aposentadoria. Os dados coletados referem-se ao período de 1989 até outubro de 2019, por meio do uso de uma ferramenta denominada de Extrator de Dados. A cada concessão de aposentadoria de um servidor, a base de dados é alimentada com as informações pertinentes, tais como: data, tipo de aposentadoria e fundamento, uma vez que todas as outras informações já foram inseridas ao longo da sua vida funcional.

Uma primeira fase de pré-processamento envolveu a limpeza, integração e seleção dos dados. Para as análises, foram utilizadas as variáveis: data de nascimento; lotação; dia da aposentadoria; fundamento da aposentadoria; tipo de aposentadoria; tipo de provento; dia do recebimento do Abono de Permanência; classe; nível; jornada de trabalho; e titulação na carreira na data da aposentadoria. Com essas variáveis foi possível realizar análises, as quais são apresentadas na seção que se segue. As análises estatísticas foram feitas com o software IBM SPSS Statistics v.20.

\section{APRESENTAÇÃO DOS RESULTADOS}

O total de todas as aposentadorias do cargo de Magistério Superior, no período que abrange o início da tramitação da primeira emenda à Constituição de 1988, até outubro de 2019, é de 419 registros de aposentados. Destes, 379 $(90,45 \%)$ eram relativos à aposentadoria voluntária. Essa informação é significativa para este estudo, uma vez que é este o tipo de aposentadoria que foi utilizado para correlacionar com as mudanças na legislação. Desta forma, a análise limita-se, a partir de agora, às aposentadorias voluntárias, entendidas como aquelas que são concedidas pelo interesse do servidor. 


\subsection{O Perfil das Aposentadorias Voluntárias e das Emendas CONSTITUCIONAIS}

Os anos que marcaram a promulgação das Emendas Constitucionais, bem como o tempo de tramitação serviram de base para as correlações com as aposentadorias. O tempo de tramitação das Emendas Constitucionais abordadas nesta pesquisa variou de oito meses a dez anos, conforme se lê no Quadro 3.

\section{Quadro 3 - A distribuição das Emendas Constitucionais no período}

\begin{tabular}{|l|l|l|l|l|}
\hline \multicolumn{2}{|c}{$\begin{array}{c}\text { Períodos com tramitação de Emendas } \\
\text { Constitucionais }\end{array}$} & \multicolumn{3}{c|}{$\begin{array}{c}\text { Períodos sem tramitação de } \\
\text { Emendas Constitucionais }\end{array}$} \\
\hline EC 03/1993 & $1991 / 1992 / 1993$ & 1989 & 2002 & 2011 \\
\hline EC 20/1998 & $1995 / 1996 / 1997 / 1998$ & 1990 & 2006 & 2012 \\
\hline EC 41/2003 & 2003 & 1994 & 2007 & 2013 \\
\hline EC 47/2005 & $2004 / 2005$ & 1999 & 2008 & 2014 \\
\hline EC 103/2019 & $2016 / 2017 / 2018 / 2019$ & 2000 & 2009 & 2015 \\
\hline
\end{tabular}

Fonte: Neiva (2020).

De acordo com o Quadro 3, desde sua promulgação, a Constituição Federal de 1988 já passou por cinco Emendas Constitucionais que alteraram alguma regra que trata da aposentadoria dos servidores públicos. Essas cinco Emendas Constitucionais juntas tramitaram por um período de 14 anos e seis meses, o que significa dizer que aproximadamente $46,6 \%$ do tempo da existência da Constituição Federal de 1988 foi vivenciado pelos servidores públicos sob expectativas de mudanças de regras na aposentadoria.

A Emenda Constitucional 88/2015 (BRASIL, 2015a), que estende a aposentadoria compulsória proporcional ao tempo de contribuição de 70 para 75 anos, não trouxe prejuízos nem desvantagens para os professores do magistério superior, portanto, não está sendo considerada nesses cálculos e nesta pesquisa.

A PEC 287/2016 (BRASIL, 2016), apresentada em 5 de dezembro de 2016 durante o governo Temer, tramitou até 4 de fevereiro de 2018 e foi arquivada, porém influenciou na Emenda Constitucional 103/2019 do governo 
Rosaura Maria Barbosa Mesquita Neiva, Nadi Helena Presser, Raimundo Nonato Macedo dos Santos, Francisco Jatobá Andrade

Impactos das emendas constitucionais nos processos de aposentadoria voluntária dos professores das Universidades Federais: gestão da informação

Bolsonaro, pois ambos defendiam os mesmos princípios liberais na economia. Portanto, seu tempo de tramitação foi contabilizado na Emenda Constitucional 103/2019 (Quadro 3).

Nos 17 anos em que não tramitaram Emendas Constitucionais, na universidade estudada, foram concedidas 87 aposentadorias voluntárias, ou seja, a média de 5,1 aposentadorias por ano. Já, nos 14 anos de tramitação das propostas de Emendas Constitucionais, foi concedida a média de 16,5 aposentadorias/ano, um aumento percentual de 223\% (Gráfico 1).

\section{Gráfico 1 - Aposentadorias voluntárias no período}

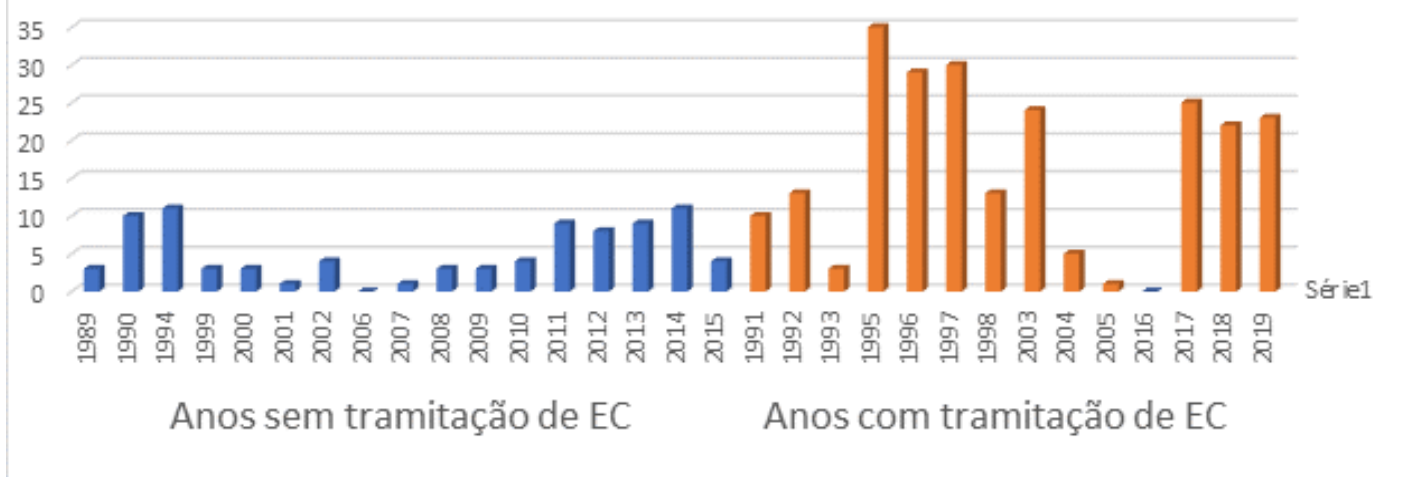

Fonte: Neiva (2020).

A decisão da aposentadoria não ocorre precisamente no ano da promulgação de uma Emenda Constitucional, mas desde uma PEC.

\subsection{O Impacto das Mudanças E O Tempo de TramitaÇÃo das Emendas À CONSTITUIÇÃo}

O Quadro 4 apresenta o resultado de uma análise documental, na qual se identificaram as principais mudanças de cada Emenda Constitucional.

Quadro 4 - Emendas Constitucionais e suas principais mudanças

\begin{tabular}{|l|l|}
\hline \multicolumn{1}{|c|}{$\begin{array}{c}\text { Emendas } \\
\text { Constitucionais }\end{array}$} & \multicolumn{1}{|c|}{ Principais Mudanças } \\
\hline $\begin{array}{l}\text { Emenda Constitucional } \\
\mathrm{n}^{\circ} \text { 03 de 1993 }\end{array}$ & $\begin{array}{l}\text { As aposentadorias dos servidores públicos federais } \\
\text { passam a ser custeadas com recursos provenientes da } \\
\text { União e das contribuições dos servidores. }\end{array}$ \\
\hline
\end{tabular}




\begin{tabular}{|c|c|}
\hline $\begin{array}{l}\text { Emenda Constitucional } \\
n^{\circ} 20 \text { de } 1998\end{array}$ & $\begin{array}{l}\text { Institui: } \\
\text { a. Tempo mínimo de } 10 \text { anos de efetivo exercício no } \\
\text { serviço público e } 5 \text { anos no cargo. } \\
\text { b. Regra de } 60 \text { anos de idade e } 35 \text { de contribuição } \\
\text { para homens e } 55 \text { de idade e } 30 \text { de contribuição } \\
\text { para mulheres. } \\
\text { c. Aposentadoria por tempo de contribuição desde } \\
\text { que alcançada a idade mínima de } 65 \text { anos para } \\
\text { homens e } 60 \text { anos para mulher. } \\
\text { Também exclui aposentadoria especial para professores } \\
\text { de nível superior. }\end{array}$ \\
\hline $\begin{array}{l}\text { Emenda Constitucional } \\
n^{\circ} 41 / 2003\end{array}$ & $\begin{array}{l}\text { Muda a forma de cálculo das aposentadorias e perdem- } \\
\text { se a integralidade e paridade. } \\
\text { Institui a contribuição previdenciária para aposentados. } \\
\text { Institui o Abono de Permanência para os ativos. }\end{array}$ \\
\hline $\begin{array}{l}\text { Emenda Constitucional } \\
n^{\circ} 47 / 2005\end{array}$ & $\begin{array}{l}\text { A contribuição previdenciária para os aposentados } \\
\text { acometidos de doenças regulamentadas passa a ser com } \\
\text { base no dobro do teto do INSS. } \\
\text { Possibilita a regulamentação por lei complementar para } \\
\text { as aposentadorias para servidores portadores com } \\
\text { deficiência, em atividades de risco ou insalubres. }\end{array}$ \\
\hline $\begin{array}{l}\text { Emenda Constitucional } \\
n^{\circ} 88 / 2015\end{array}$ & $\begin{array}{l}\text { Aposentadoria compulsória do servidor público passa a } \\
\text { ser a partir dos } 75 \text { anos. }\end{array}$ \\
\hline $\begin{array}{l}\text { Emenda Constitucional } \\
n^{\circ} 103 / 2019\end{array}$ & $\begin{array}{l}\text { Altera a forma de cálculo da aposentadoria. } \\
\text { Altera o tempo de contribuição. } \\
\text { Aumenta a idade para a aposentadoria. } \\
\text { Prevê alteração no valor do Abono de Permanência. }\end{array}$ \\
\hline
\end{tabular}

Fonte: Neiva (2020).

A Matriz das Variáveis (Quadro 5) contribui na identificação do impacto das mudanças de cada Emenda Constitucional. As emendas investidas de três ou mais variáveis foram categorizadas como "Estruturais", pois foram as que mais impactaram nas aposentadorias voluntárias. Na Matriz das Variáveis, no Quadro 5, são: EC 20/98, EC 41/03 e EC 103/2019 (BRASIL, 1998, 2003, 2019b). Tais emendas foram as que trouxeram um profundo impacto e foram regidas segundo uma visão fundamentalmente econômica, por isso mesmo, restringindo de forma significativa os direitos conquistados por meio de muita luta da classe dos trabalhadores. 


\section{Quadro 5 - Matriz das variáveis}

\begin{tabular}{|l|c|c|c|c|c|c|}
\hline \multicolumn{1}{|c|}{ Variáveis } & $\begin{array}{c}\text { EC } \\
03 / 93\end{array}$ & $\begin{array}{c}\text { EC } \\
20 / 98\end{array}$ & $\begin{array}{c}\text { EC } \\
41 / 03\end{array}$ & $\begin{array}{c}\text { EC } \\
47 / 05\end{array}$ & $\begin{array}{c}\text { EC } \\
88 / 15\end{array}$ & $\begin{array}{c}\text { EC } \\
103 / 2019\end{array}$ \\
\hline $\begin{array}{l}\text { Altera a idade para a } \\
\text { aposentadoria }\end{array}$ & & $\mathrm{X}$ & & & $\mathrm{X}$ & $\mathrm{X}$ \\
\hline $\begin{array}{l}\text { Altera o tempo para a } \\
\text { aposentadoria }\end{array}$ & & $\mathrm{X}$ & $\mathrm{X}$ & & & $\mathrm{X}$ \\
\hline $\begin{array}{l}\text { Altera a contribuição } \\
\text { previdenciária }\end{array}$ & $\mathrm{X}$ & $\mathrm{X}$ & $\mathrm{X}$ & $\mathrm{X}$ & & $\mathrm{X}$ \\
\hline $\begin{array}{l}\text { Altera a fórmula de } \\
\text { cálculo dos proventos }\end{array}$ & & $\mathrm{X}$ & $\mathrm{X}$ & & & $\mathrm{X}$ \\
\hline $\begin{array}{l}\text { Exclui direitos } \\
\text { concedidos }\end{array}$ & $\mathrm{X}$ & $\mathrm{X}$ & $\mathrm{X}$ & & & $\mathrm{X}$ \\
\hline
\end{tabular}

Fonte: Adaptado de Neiva (2020, p. 60).

A partir Matriz das Variáveis (Quadro 5) é possível visualizar três Emendas Constitucionais Estruturais e três Incrementais. Os dados aqui apresentados dão a perceber que a promulgação de tais emendas induziu os professores a garantir o que já tinham conseguido de forma tempestiva.

Nesta categoria, a pesquisa constatou que $60 \%$ das emendas enquadram-se como estruturais. Das cinco emendas analisadas, as Emendas 20/98, 41/03 e a 103/19 são as que trouxeram os mais altos níveis de impactos nas regras de aposentadoria, corroborando com o estudo de Ferraro (2006, p. 42) que classificou as ECs 20/1998 e 41/2003 como de mudanças estruturais nos sistemas de previdência, especialmente dos servidores púbicos, não sendo diferente com a recente emenda 103/2019 aprovada. Elas incluíram alterações no limite de idade, de tempo no serviço público, no cargo, na carreira; mudaram regras de cálculo das aposentadorias e formas de tributação, bem como são as que mais subtraem os direitos sociais.

As Emendas n 03/1993 e 47/2005 são aquelas que atingiram menos de três variáveis de mudanças, sendo consideradas reformas Incrementais, por trazerem baixo impacto nos pedidos de aposentadoria voluntária. A primeira instituiu a previsão de aposentadoria por contribuição, sem, no entanto, a tornar obrigatória, o que só foi determinada pela EC 20/1998, e a segunda trouxe benefícios aos portadores de doenças e aos que atuavam em condições 
específicas.

\section{Gráfico 2 - Média das aposentadorias versus Nível de Impacto das Mudanças}

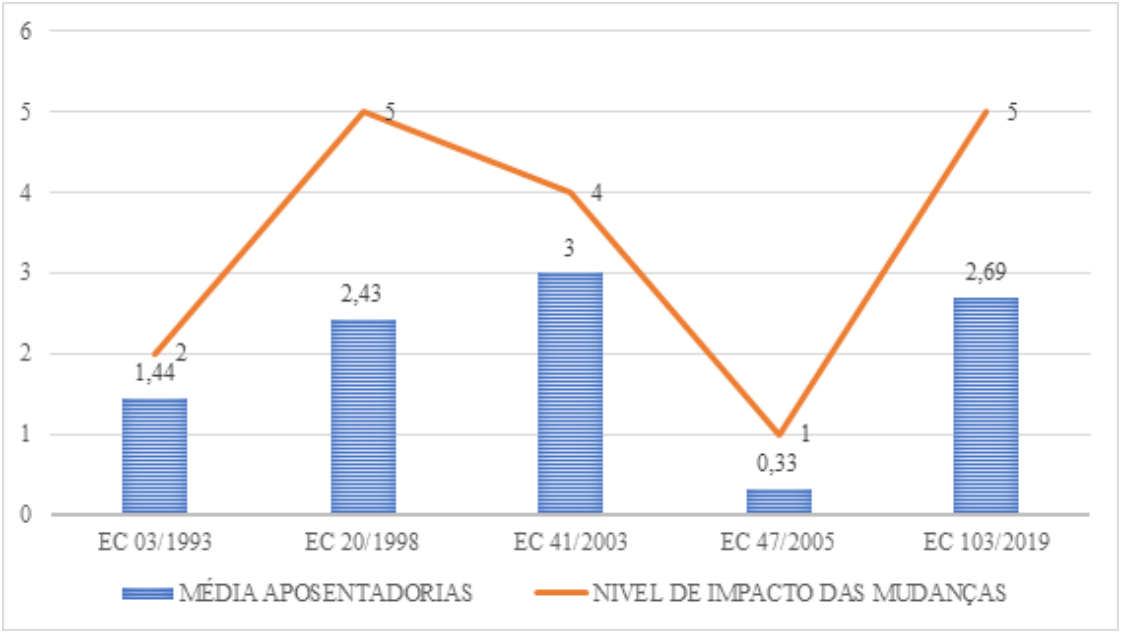

Fonte: Neiva (2020, p. 62).

De acordo com o Gráfico 2, observa-se que a média mensal das aposentadorias voluntárias parece ter uma relação direta com o Impacto das Mudanças; ela cresce na medida em que existe uma proposta de Mudança Estrutural e decresce quando se trata de uma Mudança Incremental.

Para verificar estatisticamente essa possibilidade, formula-se a hipótese $\left(\mathrm{H}_{1}\right)$ de que há uma diferença na média mensal das aposentadorias voluntárias nas Emendas Constitucionais consideradas como reformas estruturais (EC 20/1998, EC 41/2003, EC 103/2019) e nas consideradas como incrementais (EC 03/1993, EC 47/2005). Neste caso, a hipótese nula $\left(H_{0}\right)$ seria de que não existe diferença na média mensal das aposentadorias voluntárias.

O nível de mensuração da variável é intervalar ou de razão (é possível ordenar as categorias que compõem as variáveis indicando a distância entre elas). Consequentemente, para testar a significância da hipótese, bem como a associação entre as variáveis, foi necessário utilizar testes não paramétricos para dados intervalares ou de razão. Adicionalmente, como o que se procura são as diferenças nas médias entre dois grupos da mesma variável (Mudanças Estruturais e Mudanças Incrementais), utilizou-se o Teste t para amostras independentes.

As estatísticas do grupo indicam que, de um total de 233 aposentados: 
a. Se aposentaram: 201 mediante Emendas Constitucionais que apresentaram Mudanças Estruturais (86,3\%) e 32, mediante Emendas Constitucionais que apresentaram Mudanças Incrementais (13,7\%);

b. A média do tempo de tramitação das Emendas Constitucionais que apresentaram Mudanças Estruturais é de 33,43 meses, enquanto a daquelas que apresentaram Mudanças Incrementais é de 18,00 meses;

c. A amostra das Emendas Constitucionais que apresentaram Mudanças Estruturais tem uma maior variabilidade segundo indica o erro padrão das amostras, 12,52 para as Emendas estruturais e 0,00 para as Mudanças Incrementais.

Conforme os resultados do Teste $t$, a probabilidade é de 0,001 $(p=0,001<0,05)$, indicando que existem diferenças significativas entre as variâncias. Portanto, para a descrição dos resultados utilizam-se os dados correspondentes à fileira "Equal variances not assumed". A diferença entre as médias das Emendas Constitucionais é de 15,43 meses, a diferença entre o erro padrão das amostras é de 0,883 , o intervalo, com confiança de $95 \%$, para a diferença estimada das médias populacionais é de -17,17 a 13,69. Consequentemente, conclui-se que a hipótese $\mathrm{H}_{1}$ é verdadeira, ou seja, é possível afirmar com $95 \%$ de confiança que as diferenças identificadas na média mensal das aposentadorias voluntárias entre as Mudanças Estruturais e as Mudanças Incrementais nas Emendas Constitucionais não são resultado do erro amostral.

Portanto, aceita-se a hipótese $\mathrm{H}_{1}$ de que o nível estrutural das mudanças nas Emendas Constitucionais influencia no impacto das mudanças, com base no cálculo do Tempo de Tramitação das aposentadorias entre as Mudanças Estruturais e as Mudanças Incrementais, Quadro 6. Podendo-se concluir que o maior impacto no aumento das aposentadorias é gerado pelo nível estrutural das alterações.

O tempo de tramitação diz respeito ao intervalo desde a apresentação da PEC ao Congresso Nacional até a sua promulgação. 


\section{Quadro 6 - Tempo de tramitação das Emendas Constitucionais}

\begin{tabular}{|c|c|}
\hline Emendas & Tramitações \\
\hline EC 03/1993 & $\begin{array}{l}\text { PEC n 48/1991 - apresentada:19/09/1991. Promulgada:17/03/1993. } \\
\text { Tempo tramitação: } 1 \text { anos e } 6 \text { meses. }\end{array}$ \\
\hline EC 20/1998 & $\begin{array}{l}\text { PEC n 33/1995 - apresentada: 28/03/1995. Promulgada: 15/12/1998. } \\
\text { Tempo tramitação: } 3 \text { anos e } 8 \text { meses. }\end{array}$ \\
\hline EC 41/2003 & $\begin{array}{l}\text { PEC n67/2003 - apresentada: 30/04/2003. Promulgada: 31/12/2003 } \\
\text { Tempo tramitação: } 8 \text { meses. }\end{array}$ \\
\hline EC 47/2005 & $\begin{array}{l}\text { PEC n 227/2004 -apresentada: 06/01/2004. Promulgada: 05/07/2005. } \\
\text { Tempo tramitação: } 1 \text { ano e } 6 \text { meses de tramitação }\end{array}$ \\
\hline EC 88/2015 & $\begin{array}{l}\text { PEC n 42/2003-apresentada: 02/06/2003. Promulgada: 05/05/2015. } \\
\text { Tempo tramitação - } 11 \text { anos e } 11 \text { meses. }\end{array}$ \\
\hline $\begin{array}{c}E C \\
103 / 2019\end{array}$ & $\begin{array}{l}\text { PEC } n^{\circ} 06 / 2019 \text { - apresentada: } 20 / 02 / 2019 \text {. Promulgada: } 13 / 11 / 2019 \text {. } \\
\text { Tempo tramitação: } 8 \text { meses e } 27 \text { dias, mais o tempo da PEC } 287 / 2016 \\
\text { - apresentada em 05/12/2016 e que tramitou até } 04 / 02 / 2018 \text { e foi } \\
\text { arquivada, totalizando: } 26 \text { meses. }\end{array}$ \\
\hline
\end{tabular}

Fonte: Neiva (2020, p. 45).

A fim estabelecer um marco para a categoria Tramitação, foi tirada a média do tempo de tramitação das emendas: Média $=(18+44+8+18+26) / 5=$ 22,8. Por conseguinte, Tramitação Longa é o tempo de 22,8 meses ou mais e Tramitação Curta é o tempo abaixo de 22,8 meses, desde a apresentação da PEC ao Congresso Nacional até a sua promulgação. Assim, no que diz respeito à categoria Tramitação, as Emendas Constitucionais estão classificadas conforme o que se lê no Quadro 7.

\section{Quadro 7 - Classificação quanto à categoria Tramitação}

\begin{tabular}{|l|c|l|}
\hline \multicolumn{1}{|c|}{ Emendas } & $\begin{array}{c}\text { Tempo de Tramitação } \\
\text { (Meses) }\end{array}$ & \multicolumn{1}{|c|}{ Classificação } \\
\hline EC $03 / 1993$ & 18 & Curta \\
\hline EC $20 / 1998$ & 44 & Longa \\
\hline EC $41 / 2003$ & 8 & Curta \\
\hline EC $47 / 2005$ & 18 & Curta \\
\hline EC $103 / 2019$ & 26 & Longa \\
\hline
\end{tabular}

Fonte: Neiva (2020, p. 58).

A pesquisa apontou que as Emendas Constitucionais EC 20/1998 e a EC 103/2019, classificadas como de longa tramitação, também apresentaram os maiores impactos. Todavia, o mesmo não se pode afirmar da EC 41/2003. Classificada como Estrutural quanto ao Impacto da Mudança, teve, porém, um 
curto período de tramitação, demonstrando que nem sempre o impacto das alterações das Emendas Constitucionais tem uma relação direta com o Tempo de Tramitação.

O art. 60 da Constituição Federal de 1998 determina que uma Proposta de Emenda Constitucional (PEC) tramite nas duas casas que compõem o Congresso Nacional. Assim sendo, a aprovação de uma PEC depende principalmente de apoio político dos Deputados e Senadores. E, em havendo pressão da sociedade, pode-se considerar que o tempo de tramitação é impactado pelo fator político.

Os resultados encontrados a partir das análises das informações armazenadas no banco de dados da universidade indicam que houve, sim, um impacto nas aposentadorias voluntárias, da ordem de $223 \%$ a mais de pedidos.

As mudanças nas Emendas Constitucionais categorizadas como Mudanças Estruturais foram as que mais impactaram nas aposentadorias voluntárias. Todas as variáveis estudadas indicam que a EC n 103/2019 foi a que trouxe maior impacto nos pedidos de aposentadoria, seguida das Emendas Constitucionais 20/1998 e 41/2003, e, por consequência, todos os anos que apresentaram elevados números de aposentadorias foram os anos de tramitação destas emendas, 1995, 1996, 1997 e 1998 (EC 20/1998), 2003 (EC 41/2003), 2017, 2018 e 2019 (EC 103/19).

Tais emendas foram as que trouxeram um profundo impacto e foram regidas segundo uma visão econômica, por isso mesmo, restringindo de forma significativa os direitos conquistados com muita luta pela classe dos trabalhadores. As informações aqui apresentadas dão a perceber que a promulgação de tais Emendas Constitucionais induziu os professores, de maneira tempestiva, a garantir os direitos já conquistados. As dúvidas e as polêmicas causadas durante a tramitação das propostas indicam uma forte influência sobre a decisão dos professores que, de algum modo, devem ter se sentido ameaçados em seus direitos.

A matriz representada na Figura 1 ilustra nos seus quadrantes as três combinações de categorias das Emendas Constitucionais: Curta e Incremental 
- EC no. 03/1993 / EC no. 37/2003; Curta e Estrutural - EC no. 41/2003; Longa

e Estrutural - EC no. 20/1998 / EC no. 103/2019.

Figura 1 - Impacto das mudanças versus tempo de tramitação

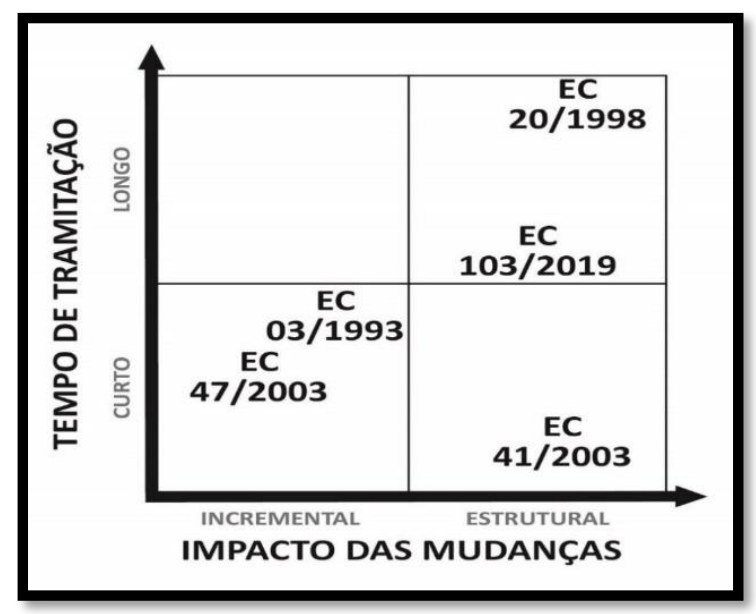

Fonte: Elaborado pelos autores (2020).

Observando a matriz da Figura 1, nota-se que todas as Emendas Constitucionais posicionadas no primeiro quadrante inferior foram de baixo impacto. Por outro lado, as emendas posicionadas nos quadrantes à direita, tanto as de curta tramitação, como as de longa tramitação, produziram maior impacto em termos de demanda de decisões de aposentadorias. Assim, a análise das informações demonstra que o Tempo de Tramitação de uma Emenda Constitucional não tem relação direta com as decisões de aposentadoria. Existe, sim, uma relação direta entre decisão de aposentadoria e o Impacto das Mudanças estabelecidas na Emenda Constitucional. Quanto mais restritivas aos direitos já adquiridos, maiores são as decisões de aposentadoria.

Assim, conforme se constata com base nas análises, fica evidenciado que as maiores concessões de aposentadorias, em atendimento a decisões por aposentadorias voluntárias, ocorreram durante as tramitações das Emendas EC 20/1998, EC 41/2003 e EC 103/2019, por isso, categorizadas, neste estudo, como Emendas Estruturais. Cabe, nesse sentido, observar que, enquanto 0 tempo de tramitação das duas primeiras Emendas Estruturais ocorreu durante um período Longo, em relação às demais, a Ementa Estrutura E103/2019 ocorre em tempo Curto de tramitação. 
Por outro lado, as Ementas EC 03/1993 e 47/2005, com tempo Curto de Tramitação, devido ao fato de seus impactos, no que se refere à concessão de aposentadorias em atendimento a decisões por aposentadorias voluntárias, terem sido pouco relevantes, foram categorizadas, por isso, no presente estudo, como Incrementais.

\section{CONSIDERAÇÕES FINAIS}

O objetivo geral desta pesquisa foi analisar as relações entre as aposentadorias voluntárias ocorridas na universidade e as mudanças estabelecidas nas Emendas Constitucionais à Constituição Federal de 1988, desde sua apresentação ao Congresso Nacional até a sua promulgação.

Os resultados encontrados a partir da gestão das informações armazenadas no banco de dados da UFRPE sinalizam que houve, sim, um impacto nas solicitações de aposentadorias voluntárias, da ordem de $223 \%$ a mais de pedidos em relação às demandas que ocorriam em anos anteriores ao início das mudanças introduzidas por meio de Emendas à Constituição Federal de 1988.

As dúvidas e as polêmicas causadas durante a tramitação das propostas indicam uma forte influência sobre a decisão dos professores que, de alguma forma, sentiram-se ameaçados em seus direitos. Dessa forma, todas as variáveis estudadas indicam que a EC $n^{\circ} 103 / 2019$ foi a que trouxe maior impacto nos pedidos de aposentadoria, seguida das Emendas $n^{\circ} 20 / 1998$ e $n^{\circ} 41 / 2003$, e, por consequência, todos os anos que apresentaram elevados números de aposentadorias foram os anos de tramitação destas emendas, 1995, 1996, 1997 e 1998 (EC 20/1998), 2003 (EC 41/2003), 2017, 2018 e 2019 (EC 103/19).

Assim, um tema central desta pesquisa constitui-se na gestão da informação, cujo núcleo de investigação é a própria informação e seus fluxos. No campo da gestão da informação, além dos resultados já demonstrados, este estudo também apontou que o banco de dados do Sistema SIAPE da universidade objeto deste estudo necessitou de uma atualização no que se referiu aos registros relativos à lotação e à titulação dos servidores aposentados. 
Foi, portanto, a partir deste estudo que o setor responsável pelo registro das informações da aposentadoria no sistema passou a registrar corretamente a lotação do professor.

O potencial das informações armazenadas no SIAPE é significativo e deve extrapolar as necessidades diárias para resolução de problemas internos. A gestão superior da universidade pode utilizá-las para estudos mais amplos que auxiliem na formulação de políticas públicas aos órgãos superiores do SIPEC.

Como sugestão para novas pesquisa, percebe-se que pode haver uma confirmação dos números aqui demonstrados, por meio de uma análise qualitativa junto aos professores aposentados.

Por fim, como consideração final, os resultados deste trabalho evidenciam que mudanças à Constituição Federal, do tipo aqui exposto, em atendimento exclusivamente a fins econômicos, geram prejuízos com perdas inestimáveis aos bens intangíveis de uma nação, representados pelos seus capitais intelectual e estrutural, respectivamente. Em nenhum momento do encaminhamento e promulgação das Emendas Constitucionais, essa soma de conhecimentos constituiu objeto de reflexões, promovendo, em decorrência, a exclusão antecipada de professores em pleno vigor da sua produção intelectual de alto nível, com a consequente descontinuidade, desorganização e desestruturação do patrimônio intelectual e cultural da nação, construído com enorme esforço, investimento, visão de futuro dos mestres que nos antecederam.

\section{REFERÊNCIAS}

BEAL, Adriana. Gestão estratégica da informação: como transformar a informação e a tecnologia da informação em fatores de crescimento e de alto desempenho nas organizações. São Paulo: Atlas, 2004.

BRASIL. Constituição da República Federativa do Brasil de 1988. [1988]. Disponível em:

http://www.planalto.gov.br/ccivil_03/constituicao/constituicaocompilado.htm Acesso em: 13 maio 2020. 
BRASIL. Decreto n 99.328, de 19 de junho de 1990. [1990]. Disponível em: http://www.planalto.gov.br/ccivil_03/decreto/1990-1994/D99328.htmAcesso em: 03 jun. 2019.

BRASIL. Lei no. 8.212 de 24 de julho de 1991. [1991]. Disponível em: http://www.planalto.gov.br/ccivil_03/leis//8212cons.htm. Acesso em: 13 maio 2020.

BRASIL. Emenda Constitucional nº 03 de 1993. [1993a]. Disponível em: http://www.planalto.gov.br/ccivil_03/constituicao/emendas/emc/emc03.htm Acesso em: 13 maio 2020.

BRASIL. Lei $\mathbf{n}^{\circ}$. 8.745, de 09 de dezembro de 1993. [1993b]. Disponível em: http://www.planalto.gov.br/ccivil_03/Leis/L8745cons.htm Acesso em: 04 jun. 2019.

BRASIL. Emenda Constitucional $n^{\circ} .20$ de 1998. [1998]. Disponível em: http://www.planalto.gov.br/ccivil_03/constituicao/emendas/emc/emc20.htm Acesso em: 13 maio 2020.

BRASIL. Emenda Constitucional $n^{\circ} .41$ de 2003. [2003]. Disponível em: http://www.planalto.gov.br/ccivil_03/constituicao/Emendas/Emc/emc41.htm Acesso em: 13 maio 2020.

BRASIL. Emenda Constitucional $n^{\circ} .47$ de 2005. [2005]. Disponível em: http://www.planalto.gov.br/ccivil_03/constituicao/emendas/emc/emc47.htm Acesso em: 13 maio 2020.

BRASIL. Ministério do Planejamento, Orçamento e Gestão. Instrução Normativa ${ }^{\circ}$ 04/2006. [2006]. Disponível em:

https://legis.sigepe.planejamento.gov.br/legis/detalhar/2563 Acesso em: 01 jun. 2019.

BRASIL. Decreto no 7.485, de 18 de maio de 2011. [2011]. Disponível em: http://www.planalto.gov.br/ccivil_03/_Ato2011-/Decreto/D7485.htm Acesso em: 13 maio 2020.

BRASIL. Emenda Constitucional $\mathrm{n}^{\circ} 88$ de 7 de maio de 2015. [2015a]. Disponível em: http://www.planalto.gov.br/ccivil_03/constituicao/Emendas/Emc/emc88.htm Acesso em: 13 maio 2020.

BRASIL. Lei Complementar $n^{\circ}$ 152, de 03 de dezembro de 2015. [2015b]. Disponível em: http://www.planalto.gov.br/ccivil_03/leis/lcp/Lcp152.htm Acesso em: 5 maio 2020. 
BRASIL. PEC n²87 de 2016. [2016]. Disponível em:

https://www.camara.leg.br/proposicoesWeb/fichadetramitacao?ldProposicao=2 119881 Acesso em: 13 maio 2020.

BRASIL. Ministério do Planejamento, Desenvolvimento e Gestão. Manual de Procedimentos: Aposentadoria. Ministério do Planejamento, Desenvolvimento e Gestão, Secretaria de Gestão de Pessoas. 1. ed. Brasília: MP, 2017. 103 p.

BRASIL. Decreto no 9.739, de 28 de março de 2019. [2019a]. Disponível em: http://www.planalto.gov.br/ccivil_03/_ato2019-2022/2019/decreto/D9739.htm Acesso em: 13 maio 2020.

BRASIL. Emenda Constitucional n ${ }^{\circ} 103$ de 12 de novembro de 2019. [2019b]. Disponível em:

http://www.planalto.gov.br/ccivil_03/constituicao/emendas/emc/emc103.htm Acesso em: 12 jan. 2020.

$\mathrm{CHOO}$, Chun Wei. Information management for the intelligent organization: the art of scanning the environment. 2. ed. Medford, New Jersey: ASIS Monograph Series, 1998.

DAVENPORT, Thomas. Hayes. PRUSAK, Laurence. Ecologia da Informação: porque só a informação não basta para o sucesso na era da informação. São Paulo: Futura, 1998. 316 p.

FAGNANI, Eduardo. Previdência social: reformar ou destruir? In: JINKINGS, Ivana; DORIA, Kim; CLETO, Murilo. (eds.). Por que gritamos golpe? Para entender o impeachment e a crise. São Paulo: Boitempo, 2016. p. 85-92.

FAZIO, Luciano. A capitalização e o regime geral de previdência social: elementos de análise. [2019]. Disponível em: https://apabanese.org.br/wpcontent/uploads/2019/02/FAZIO-Previdencia-capitalizada.pdf. Acesso em: 13 maio 2020.

FERRARO, Suzani Andrade. As Emendas Constitucionais n²0/1998 e 41/2003 e o equilíbrio financeiro e atuarial nos regimes de previdência social. 2006. 228 f. Dissertação (Mestrado em Direito) - Pontifícia Universidade Católica, São Paulo, 2006. Disponível em : https://tede2.pucsp.br/handle/handle/7676. Acesso em: 1 dez. 2019.

FLEMING-MAY, Rachel. Anne. "Use" in the 647onceptual of Library and Information Science: A concept analysis and typology. 2008. 192 p.

Dissertation (degree of Doctor of Philosophy - Department of Communication \& Information Sciences) - Graduate School of The University of Alabama. Tuscaloosa, Alabama, 2008.

FUNDAÇÃO DE PREVIDÊNCIA COMPLEMENTAR DO SERVIDOR PÚBLICO FEDERAL DO PODER EXECUTIVO (FUNPRESP-EXE). Diferenças entre 
RPPS, RGPS e RPC. 2019. Disponível em:

https://www.funpresp.com.br/portal/paginas/2013/02/16 Acesso em: 28 ago. 2019.

GIL, Antônio Carlos. Métodos e técnicas de pesquisa social. 6. ed. São Paulo: Atlas, 2008. 197p.

JOHNSON, J. David. An impressionistic mapping of information behavior with special attention to contexts, rationality, and ignorance. Information Processing and Management, [s.I.], v. 45, p. 593-604, 2009.

LE COADIC, Yves-François. A ciência da informação. 2. ed. Brasília, DF: Briquet de Lemos Livros, 2004.

LOURENÇO, Edvânia Ângela de Souza; LACAZ, Francisco Antonio de Castro; GOULART, Patrícia Martins. Crise do capital e o desmonte da previdência social no Brasil. Serv. Soc. Soc., São Paulo, n. 130, p. 467-486, set./dez. 2017.

MCGEE, James; PRUSAK, Laurence. Gerenciamento estratégico da informação: aumente a competitividade e a eficiência da sua empresa utilizando a informação como uma ferramenta estratégica. Rio de Janeiro: Campus, 1994.

NEIVA, Rosaura Maria Barbosa Mesquita. Gestão da informação aplicada aos processos de aposentadoria dos professores da UFRPE: uma análise frente às emendas constitucionais à Constituição de 1988. 92 folhas. 2020. Dissertação (Mestrado em Gestão Pública) - Universidade Federal de Pernambuco, CCSA, 2020.

PORTO, Vilson; CAETANO, Marcelo. A previdência dos servidores públicos federais: um regime sustentável? In: CONGRESSO CONSADA DE GESTÃO PÚBLICA, 8., 2015, Brasília. Anais [...]. Brasília, DF: CONSADA, 2015.

VERGARA, Sylvia Constant. C. Projetos e relatórios de pesquisa em administração. 16. ed. São Paulo: Atlas, 2016.

\section{IMPACTS OF THE CONSTITUTIONAL AMENDMENTS ON THE PROCESSES OF THE VOLUNTARY RETIREMENT OF PROFESSORS AT FEDERAL UNIVERSITIES: INFORMATION MANAGEMENT.}

\footnotetext{
ABSTRACT

Introduction: Voluntary retirement is an early retirement granted to civil servants who have completed the minimum requirements established in the Federal Constitution.
} 
Objective: This paper analyzes the relationship between voluntary retirement granted at the Federal universities and the changes established in the amendments to the 1988 Federal Constitution, since the moment it was presented to the National Congress, until its promulgation. Methodology: It is a descriptive and explanatory research, looking for a relationship between two phenomena: the voluntary retirement of professors and the Amendments to the 1988 Federal Constitution dealing with that issue. Data collection was performed through documentary research, as well as in the database of the Integrated System for Management of Human Resources (SIAPE). Results: The research points out a direct relationship between the voluntary retirement requests and changes in retirement rules that took place from the very beginning of the amendments. Conclusions: There was a $223 \%$ increase in the number of requests for voluntary retirements in relation to those that had taken place before the introduction of Amendments to the Federal Constitution of 1988.

Descriptors: Voluntary retirement of professors. Federal Public University. Amendments to the 1988 Federal Constitution. Information Management.

\title{
IMPACTOS DE LAS ENMIENDAS CONSTITUCIONALES EN LOS PROCESOS DE RETIRO VOLUNTARIO DE LOS PROFESORES DE LAS UNIVERSIDADES FEDERALES: GESTIÓN DE LA INFORMACIÓN.
}

\begin{abstract}
RESUMEN
Introducción: El retiro voluntario es un retiro anticipado otorgado a los funcionarios que han cumplido los requisitos mínimos establecidos en la Constitución Federal. Objetivo: El trabajo analiza la relación entre los retiros voluntarios otorgadas en las universidades federales y los cambios establecidos en las Enmiendas a la Constitución Federal de 1988, desde su presentación al Congreso Nacional hasta su promulgación. Metodología: Es una investigación descriptiva y explicativa, que busca la relación entre dos fenómenos: el retiro voluntario de los profesores y las enmiendas a la Constitución de 1988 que tratan sobre el tema. La recolección de datos se realizó a través de investigación documental y en la base de datos del Sistema Integrado de Administración de Personal (SIAPE). Resultados: La investigación señala que existe una relación directa entre las solicitudes de retiro voluntario y los cambios en las reglas de retiro, desde el mismo comienzo de las enmiendas. Conclusiones: El número de solicitudes de retiros voluntarios se incrementó en $223 \%$ con relación a las que ocurrieron antes de la introducción de las Enmiendas a la Constitución Federal de 1988.
\end{abstract}

Descriptores: Retiro voluntario de profesores. Universidad Pública Federal. Enmiendas a la constitución de 1988. Gestión de la información.

Recebido em: 16.05 .2020

Aceito em: 04.07.2020 